Article

\title{
Consumer Purchase Intentions for Sustainable Wild Salmon in the Chinese Market and Implications for Agribusiness Decisions
}

\author{
Qiujie Zheng ${ }^{1}$, H. Holly Wang ${ }^{2,3, *}$ and Yonggang $\mathrm{Lu}^{4}$ \\ 1 Department of Economics and Public Policy, University of Alaska Anchorage, Anchorage, AK 99508, USA; \\ qzheng3@alaska.edu \\ 2 Institute of Agricultural Resources and Regional Planning, Chinese Academy of Agricultural Sciences, \\ Beijing, 100080, China \\ 3 Department of Agricultural Economics, Purdue University, West Lafayette, IN 47907, USA \\ 4 Department of Information Systems and Decision Sciences, University of Alaska Anchorage, \\ Anchorage, AK 99508, USA; ylu4@alaska.edu \\ * Correspondence: wanghong@purdue.edu; Tel.: +1-765-494-4245
}

Received: 28 February 2018; Accepted: 25 April 2018; Published: 28 April 2018

\begin{abstract}
Sustainable food consumption and production play an increasingly important role in improving food security and quality in the food system worldwide. Consumers' food consumption patterns in China, a rapidly emerging economy with the largest population and one of the largest consumer markets in the world, significantly influence the structure of global trade flows and the sustainable ecosystem and environment. In this paper, we assess the emerging demand for imported wild and sustainable Alaskan salmon fillet and varietal parts in China's market through consumers' stated purchase intentions for the products. We use an ordered logit model to link consumers' purchase intentions with potential influencing factors and identify important factors, including consumers' consumption habits, perceptions, and social demographic characteristics. Due to differences between western and Chinese consumers on how different parts of fish are consumed, seemingly low-value salmon heads and bones may carry significant value if being imported and sold to Chinese consumers. We believe that our study is an important step in helping to build a sustainable business model, thereby creating a win-win situation for both the importing and exporting countries in order to allocate resources efficiently, feed people with healthy food, avoid food waste, and fulfill the economic value of products.
\end{abstract}

Keywords: sustainability; consumption; purchase intentions; wild salmon; China market

\section{Introduction}

With global population growth and social demographic changes, sustainable food consumption and production play an increasingly important role in ensuring food security and improving food quality in the global system. Sustainable development in the agricultural and food sector includes the ecological component of preserving the environment and using natural resources in a sustainable way, and the social component of integrating agriculture with the needs of society and gaining support from both the public and governments [1]. Understanding consumers' attitudes towards sustainable food consumption and designing a sustainable production and supply system will help the industry to utilize natural resources along the food value chain efficiently, as well as reduce food waste [2] and the excess use of chemicals that contaminate the environment [3].

China, as an emerging economy with the largest population in the world, has experienced rapid economic development in the last three decades. Accordingly, Chinese consumers' food 
preferences and consumption patterns have been moving in a consistent direction and catching up with the world trend. With the rise of a middle-class earning a significant disposable income, there emerges a large consumer segment that cares about quality and pursues high-end food products [4]. Due to environmental pollution and a number of food-safety scandals in China in recent years, Chinese consumers have growing concerns about food safety and possible contamination of the domestic food supply. This creates a strong demand for food sourced from clean, safe and natural environments, especially imported products of good quality and reputation. In addition, under the "Belt and Road" initiative proposed by the Chinese government aiming to promote China's international cooperation and efficient resource allocation, environmental sustainability is becoming a significant factor influencing production and consumption decisions.

China's seafood market is the largest in the world [5] and an increasing proportion of that is from imported sources [6]. A significant proportion of seafood products imported into China is processed and then re-exported to other countries; the rest is consumed domestically, especially the species not produced locally $[7,8]$. Imported salmon, a highly valued seafood, has gained increasing popularity among Chinese consumers due to its health benefits and taste [9]. Currently, farm-raised salmon from Norway and Chile are dominating the Chinese market, while wild salmon, such as Alaska salmon, from clean and natural environments, are sold only in a few upscale restaurants and not yet available to mass consumers. However, since its natural and safe production environment results in superior food quality, wild salmon has begun to attract consumers' attention. According to 2012 data, Alaska sockeye salmon exports have risen, which reflects a growing demand from Chinese consumers for highly valued wild seafood [10].

In the meantime, there are significant differences between western and Chinese consumers on how different parts of fish are consumed. In the US, for example, most consumers only eat salmon fillet. Even though other varietal cuts or parts of salmon are sold in the market occasionally, their prices are usually very low. In contrast, it is well known that Chinese culinary traditions include the cooking of fish heads, tails and bones for various soups and stews that are considered to be healthy meals. These salmon varietal parts are usually displayed together with fillets for sale in supermarkets, and they may carry significant value if being imported and sold to Chinese consumers. This potential not only helps enhance the economic value of salmon for producers, but also contributes to the sustainable use of natural resources and waste minimization in the global food system.

In this paper, we assess the emerging demand for imported wild and sustainable salmon fillet and varietal parts from Alaska in China's market through consumers' stated purchase intentions for the products. We build a model to link consumers' purchase intentions with potential influencing factors, including consumers' seafood and salmon consumption habits, perceptions on sustainable production environments, taste, and nutrition of seafood from such environments, and social demographic variables. The objectives of the paper are (1) to understand Chinese consumers' purchase intentions of imported wild salmon, which is harvested through sustainable fishing practices in natural and pure environments; (2) to examine the factors that affect the potential purchase of the products and provide insights into consumer segmentations that show a preference for the sustainable seafood; and (3) to provide guidance on the sustainable business potential for the entire seafood value chain and policy implications in order to align production with consumption in a sustainable way for policy-makers.

\section{Background and Literature}

There are two methods for quantifying consumers' preference, the revealed preference and stated preference methods. The former applies to goods already existing in the market, and researchers use observations on actual choices to measure the influence on consumer behavior of market or policy factors such as price, labeling mandates, information in the advertisement and media reports, and income [11-13]. The latter applies to emerging goods or even hypothetical goods not yet in the market or attributes of goods that are not observable. 
Currently, the stated preference methods become popular because the market is more consumer driven, and new products and new concepts of producing and promoting products are introduced into markets at an accelerating rate. Many of such products or concepts are relevant to sustainable practice, such as locally grown food, organic food, and food with animal welfare attributes. Most of these studies used survey-based stated preference methods that provide the flexibility to elicit consumers' preferences for existing or hypothetical attributes.

Over the last three decades, a rich literature on consumer demand for food attributes has developed and the research consistently demonstrates that consumers value food attributes, both intrinsic and extrinsic ones. Some extrinsic attributes only provide external benefits and do not necessarily affect the intrinsic attributes of food. Consumers show a preference and willingness to pay for these attributes such as animal welfare [14-16] and fair trade or labor practices [17-19] for the benefit to the public instead of their own individual benefit.

Other attributes directly affect the taste and health content of the food products, and thus the well-being of the consumers, such as food-safety characteristics, country of origin, eco-friendliness, organic or sustainable production practice. Food safety is always a concern and consumers are skeptical about the use of pesticides, genetic modification, antibiotics, and other substances or technology. Consumers are found to be willing to pay a premium for foods that avoid these methods [20-22]. A large number of studies also confirm that consumers are willing to pay for country-of-origin labels (COOL) showing a preference for food from home countries or developed countries [23-26], not only because they are ethnocentric but also because they believe the COOL signals high quality [27]. Consumers have shown purchase intentions or willingness to pay for ecolabeled products because of environmental and/or food-safety concerns [28-30]. Consumers' valuations of organic food or sustainable food are also elevated [31-33], because it not only preserves the environment but also may improve intrinsic attributes such as taste and nutrition. Consumers perceive food of this kind as tastier, safer and healthier, as well as being environmentally and animal friendly $[34,35]$.

Most of the aforementioned research has investigated consumers in developed countries. The concepts of organic or sustainable production practice are still relatively new to consumers in China, an emerging economy. Although there is some research about Chinese consumer purchase intentions [36,37], attitudes [38,39], motives [40] or support [41] for organic or sustainable food, the categories studied are general organic foods or vegetables. There is very limited research on Chinese consumers' preferences for sustainable food in a specific category, such as seafood, the production and harvest of which significantly affect environmental sustainability.

Chinese consumers have growing awareness of health and environmental issues related to food production [41]. While there is an argument about the integration of human health and environment into the field of food [42,43], some research recommended that health should be the principle to change consumer behavior since personal benefit may have a greater potential to support behavior change $[44,45]$. Therefore, it is important to assess the effects of the production environment, health and nutrition content benefits resulting from sustainable production practices on Chinese consumers' potential purchases in order to understand their preferences for seafood that follows sustainable production practice.

Our study will contribute to the literature by providing an in-depth understanding about Chinese consumers' purchase intentions for wild sustainable seafood, specifically salmon. Since wild salmon is not widely available in the Chinese market yet, a purchase intention survey is a helpful tool to forecast consumer's behavior and the market potential of emerging products [46,47]. Many studies have examined the causal relationship between various determinants and purchase intentions. Consumers' familiarity and prior experience with the product, attitudes towards it, and perceptions of its attributes are all potential determinants affecting purchase intentions [48-51]. Consumers' characteristics are also important in determining their purchase intentions [49]. In addition, researchers relate purchase intentions to the perceived value of a product which is determined by consumers' perceptions of the quality and price of the product [52-55]. In this study, we follow 
the conceptual relationship between perceived value and purchase intentions to build a model linking potential determining factors with consumers' purchase intentions for Alaska salmon fillet and heads/bones. A particular contribution of this study is that our selection of studying salmon fillet and heads/bones facilitate us to propose a very practical agribusiness model to align food production and distribution to consumption in a sustainable way under the global food system framework.

\section{Methodology}

\subsection{Conceptual Framework}

Since Alaskan wild salmon is relatively new to mass Chinese consumers, we examine consumer stated intentions to purchase wild salmon fillet and heads/bones and identify important factors that affect their purchase intentions. Consumers' purchase intentions are affected by their perceived value (perceived value was developed in previous studies in multiple dimensions including social, emotional, functional, epistemic and conditional value [56-58]. In this paper, we simplified the mechanism of perceived value and emphasized the impact of consumers' perceptions on product attributes including production environment, taste and nutrition content on perceived value and thus purchase intention. Further dimensions of perceived value may be considered in future research) of the salmon that is determined by their perceptions of the quality and price of the product. Their perceptions on the quality of wild sustainable salmon derive from their attitudes towards the extrinsic and intrinsic attributes of the product. Consumers who perceive positive benefits of clean production environment, superior taste, and higher nutrition content from Alaskan wild sustainable salmon may consider that the product has a higher quality and, thus, have greater intentions to purchase it. The extrinsic environmental benefits may affect the taste and nutrition content of the product which altogether result in a higher perceived quality. In addition, prior experience such as previously established seafood consumption habits and salmon consumption preferences may affect consumers' intentions to purchase new products. Social demographic information that describes consumers' characteristics are important factors affecting their purchase intentions. Figure 1 shows the conceptual framework describing the important factors that potentially affect consumers' purchase intentions for Alaskan wild salmon. Although both salmon fillet and heads/bones are sustainably harvested, the effects of different factors on purchase intentions may vary between the fillet and varietal parts due to the different nature of these two products.

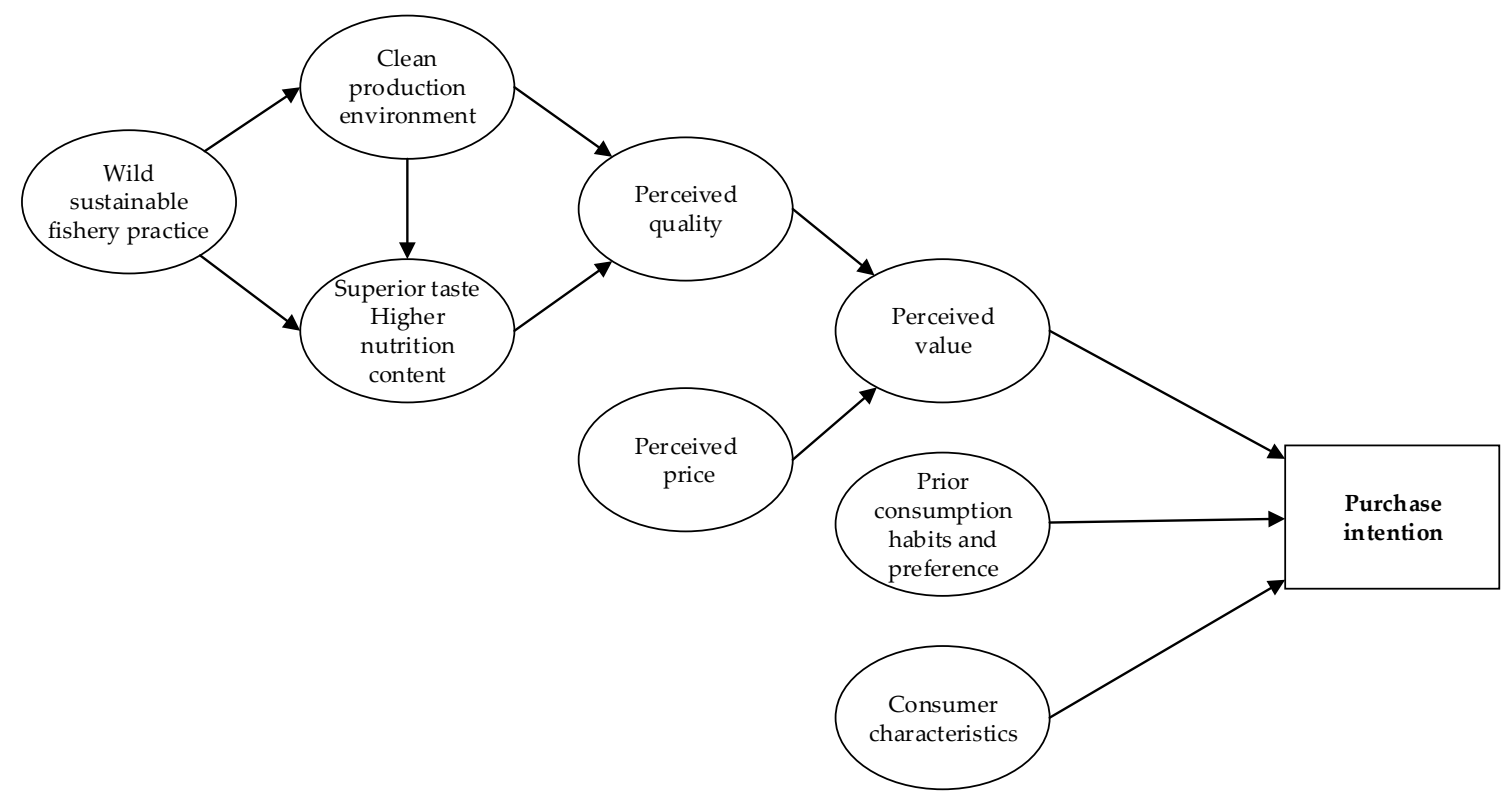

Figure 1. Conceptual framework. 


\subsection{Model}

Economic theory states that consumers make their consumption choices to maximize their utilities, subjective values measuring their satisfaction, under certain constraints, such as budget and availability constraints. They make a consumption choice only if that choice brings them higher utility than other choices under the same constraints. The utility, or satisfaction, may be based on the quantity, quality, and cost of consumption goods, and attributes such as sustainability and altruistic factors. It is also different across individuals, so that an individual consumer's own characteristics also affect the utility levels.

In our study, assuming the utility can be represented by the common random utility function with linear specifications, the utility of individual $i, U_{i}{ }^{*}$, can be represented as:

$$
U_{i}^{*}=x_{i}^{\prime} \beta+\varepsilon_{i}
$$

where $x_{i}$ represents a vector of factors affecting the utility from buying the product, $\beta$ denotes the corresponding coefficients, and $\varepsilon_{i}$ represents the unobserved random component that is assumed to be logistically distributed.

The consumer choices we investigate in this study are their stated intentions to purchase the products by choosing one of five categories. Variable $Y_{i}$ records the response and assumes values as 1 if the response is "Definitely would not buy it", 2 if "Probably would not buy it", 3 if "Might or might not buy it", 4 if "Probably would buy it", and 5 if "Definitely would buy it". The ordered responses represent a censored version of the consumer's true underlying utility, $U_{i}^{*}$. Higher levels of $U_{i}^{*}$ indicate that the consumer has a higher intention to buy the product and lower levels mean the consumer has a lower intention to buy it. Following [59], the consumer's decision is represented by the underlying utility as:

$$
Y_{i}= \begin{cases}\text { 1, i.e. "Definitely would not buy it" } & \text { if } \mu_{0}<\mathrm{U}_{\mathrm{i}}^{*} \leq u_{1} \\ 2, \text { i.e. "Probably would not buy it" } & \text { if } u_{1}<\mathrm{U}_{\mathrm{i}}^{*} \leq u_{2} \\ 3, \text { i.e. "Might or might not buy it" } & \text { if } u_{2}<\mathrm{U}_{i}^{*} \leq u_{3} \\ 4 \text {, i.e. "Probably would buy it" } & \text { if } u_{3}<\mathrm{U}_{i}^{*} \leq u_{4} \\ \text { 5, i.e. "Definitely would buy it" } & \text { if } u_{4}<\mathrm{U}_{\mathrm{i}}^{*} \leq u_{5}\end{cases}
$$

where $u_{k}(k=1,2, \ldots, 5)$ indicates the utility threshold level corresponding to each decision category. Particularly, $u_{0}=-\infty$ and $u_{5}=+\infty$.

The probability of observing a respondent choosing a particular purchase intention category equals the probability that their utility is within the range of the threshold levels of that category. The probability of observing a specific response $Y_{i}=j, j=1,2, \ldots, 5$ for individual $i$ is:

$$
\begin{aligned}
\mathrm{P}\left(Y_{i}=j\right) & =\mathrm{P}\left(u_{(j-1)}<U_{i} * \leq u_{j}\right) \\
& =\mathrm{P}\left(u_{(j-1)}<x_{i}{ }^{\prime} \beta+\varepsilon_{i} \leq u_{j}\right) \\
& =\mathrm{P}\left(u_{(j-1)}-x_{i}{ }^{\prime} \beta<\varepsilon_{i} \leq u_{j}-x_{i}{ }^{\prime} \beta\right) \\
& =\frac{e^{u_{j}-x_{i}^{\prime} \beta}}{1+e^{u_{j}-x_{i}{ }^{\prime} \beta}}-\frac{e^{u_{(j-1)}-x_{i}{ }^{\prime} \beta}}{1+e^{u_{(j-1)}-x_{i}{ }^{\prime} \beta}}, \text { for } j=1,2, \ldots, 5
\end{aligned}
$$

The likelihood function is obtained by multiplying the probabilities across all respondents. Maximizing the log likelihood function provides the estimates of coefficients and the threshold levels for the ordered logit model.

The exponential value of the estimated coefficient is the odds ratio which is the ratio of the cumulative odds of the dependent variable belonging to a certain category or higher versus its 
belonging to the lower categories, i.e., $P\left(Y_{i} \geq j\right) / P\left(Y_{i}<j\right)$ where $j=1, \ldots, 5$. In the ordered logit model, these odds are assumed constant for any category $j$.

We implemented the ordered logit model procedure in Stata 14 (Code is available upon request) to examine potential impact factors on consumer's purchase intentions for wild salmon fillet and heads/bones from Alaska, respectively.

\subsection{Survey and Data}

We recruited local graduate students to administer the survey during June and July 2015 at three representative cities in China including Beijing, Shanghai, and Guangzhou. Consumers living in the three topline cities have relatively higher purchasing power and easier access to upscale grocery outlets to buy imported foods. In each city, we selected nine representative large supermarkets or hypermarkets (such as Carrefour and Walmart) in the districts within the urban area and each of them carried fresh salmon in the seafood department. Teams of two trained student interviewers conducted the surveys at the supermarkets randomly assigned to them. They randomly invited shoppers from the supermarkets to participate in the survey with cash compensation to the respondents. If the randomly invited shopper refused to participate in the survey, they randomly asked another shopper about interests in participation. In total, we interviewed 1028 respondents and obtained 1017 valid observations with complete information, with 339 in Beijing, 338 in Shanghai, and 340 in Guangzhou.

Table 1 presents descriptive statistics of the social demographic variables representing consumer characteristics. In our survey, $35 \%$ of respondents were male and $65 \%$ were female. The fact that female respondents outnumber males by almost $100 \%$ is consistent with many other consumer surveys conducted at shopping sites. For most households, the female household members usually do the grocery shopping. The average age of the respondents was 37 years old, with a range from 18 to 85 years old. Twenty-six percent of the respondents had high school or lower education, $22 \%$ had some college education including vocation school or an associate degree, 37\% had a bachelor's degree, and $15 \%$ had a graduate degree. On average, each household had 3.6 people and half of them had children living with them. The average annual household income was 130,000 RMB (around \$21,000 USD). Over the past two years, $51 \%$ of the respondents experienced an income increase, $3 \%$ experienced an income decrease, and $46 \%$ had their income remain the same. Twenty-four percent of the respondents had migrated from small towns or rural areas to cities over the past two years.

Table 1. Descriptive statistics of consumer characteristic variables.

\begin{tabular}{llll}
\hline Variable & Description & Mean (\%) & Std Dev \\
\hline age & Age in years & 37.20 & 13.51 \\
hhnum & Number of household members & 3.63 & 1.59 \\
income & Annual household income (in ten thousands of RMB) & 13.00 & 6.11 \\
male & Male & $0.35(35 \%)$ & 0.48 \\
edu_hs & High school or lower & $0.26(26 \%)$ & 0.44 \\
edu_col & Vocational school or associate & $0.22(22 \%)$ & 0.42 \\
edu_ba & Bachelor's degree & $0.37(37 \%)$ & 0.48 \\
edu_grad & Graduate degree & $0.15(15 \%)$ & 0.35 \\
$\boldsymbol{d}$ child & Children presence & $0.50(50 \%)$ & 0.50 \\
inc_in & Income increase over last two years & $0.51(51 \%)$ & 0.50 \\
inc_de & Income decrease over last two years & $0.03(3 \%)$ & 0.18 \\
inc_sa & Income stay the same over last two years & $0.46(46 \%)$ & 0.50 \\
migrant & Migrate to city over last two years & $0.24(24 \%)$ & 0.43 \\
city_BJ & Beijing & $0.33(33 \%)$ & 0.47 \\
city_SH & Shanghai & $0.33(33 \%)$ & 0.47 \\
city_GZ & Guangzhou & $0.33(33 \%)$ & 0.47 \\
\hline
\end{tabular}

Note: All variables are dummies except age, hhnum, and income, which are continuous variables.

Table 2 shows descriptive statistics of potential determining variables including respondents' seafood purchase habits, salmon consumption preference and perceptions on wild vs. farm-raised seafood in terms of production environment, taste and nutrition content. As shown in Figure 1, those variables are potential determining factors on consumers' purchase intentions. Regarding 
preference for seafood harvest methods, $25 \%$ of the respondents often buy wild seafood, $40 \%$ buy both wild and farm-raised seafood, $11 \%$ often buy farm-raised seafood, and $24 \%$ do not pay attention to, or do not understand, the difference. The last two groups combined form a segment of $64 \%$ of consumers who do not have a strong preference for the seafood harvest method.

Table 2. Descriptive statistics of purchase habits, consumption preference and perception variables.

\begin{tabular}{|c|c|c|c|c|}
\hline Variable & & Description & Mean (\%) & Std Dev \\
\hline \multirow{4}{*}{ Harvest Method } & harvest_wild & Often buy wild seafood & $0.25(25 \%)$ & 0.43 \\
\hline & harvest_both & Often buy both wild and farm raised seafood & $0.40(40 \%)$ & 0.49 \\
\hline & harvest_farm & Often buy farm raised seafood & $0.11(11 \%)$ & 0.32 \\
\hline & harvest_none & Does not pay attention to the difference & $0.24(24 \%)$ & 0.43 \\
\hline \multirow{4}{*}{ Preservation Method } & pres_water & Often buy fish preserved in water tank & $0.76(76 \%)$ & 0.43 \\
\hline & pres_chill & Often buy chilled fish & $0.11(11 \%)$ & 0.31 \\
\hline & pres_froze & Often buy frozen fish & $0.05(5 \%)$ & 0.22 \\
\hline & pres_other & No strict preference for preservation method & $0.08(8 \%)$ & 0.27 \\
\hline \multirow{4}{*}{ Preparation method } & cook_raw & Often eat salmon raw, sashimi or sushi & $0.66(66 \%)$ & 0.48 \\
\hline & cook_fry & $\begin{array}{l}\text { Often eat salmon pan fried, deep fried or } \\
\text { grilled }\end{array}$ & $0.13(13 \%)$ & 0.34 \\
\hline & cook_stew & Often eat salmon steamed, boiled or stewed & $0.15(15 \%)$ & 0.36 \\
\hline & cook_other & Often cook salmon using other methods & $0.06(6 \%)$ & 0.24 \\
\hline \multirow{4}{*}{ Dining Venue } & place_home & Often eat salmon at home & $0.21(21 \%)$ & 0.40 \\
\hline & place_restarant & Often eat salmon at restaurants & $0.46(46 \%)$ & 0.50 \\
\hline & place_both & Often eat salmon at home and restaurants & $0.28(28 \%)$ & 0.45 \\
\hline & place_other & Often eat salmon at other venues & $0.05(5 \%)$ & 0.21 \\
\hline \multirow{3}{*}{ Perceptions } & clean & $\begin{array}{l}\text { Perceive Alaska as a high quality, safe and } \\
\text { clean seafood production environment }\end{array}$ & $0.57(57 \%)$ & 0.50 \\
\hline & tasty & $\begin{array}{l}\text { Perceive Alaskan wild seafood tastes better } \\
\text { than farm raised seafood }\end{array}$ & $0.57(57 \%)$ & 0.49 \\
\hline & nutritious & $\begin{array}{l}\text { Perceive Alaskan wild seafood as more } \\
\text { nutritious than farm-raised seafood }\end{array}$ & $0.53(53 \%)$ & 0.50 \\
\hline
\end{tabular}

Note: All variables are dummies, and the means are the percentages falling in the corresponding categories.

In the survey, we asked respondents to provide the proportions of fish they purchased in 2014 that are live in water tanks at stores, chilled, or frozen, respectively. We consider the respondents having an obvious preference for a specific preservation method if the proportion of their 2014 fish purchase in that form is larger than that of the other two forms. Seventy-six percent of the respondents preferred live fish in water tanks, $11 \%$ preferred chilled fish, $5 \%$ preferred frozen fish, and $8 \%$ did not show a clear preference one way or another.

Regarding salmon cooking methods, $66 \%$ of the respondents often ate salmon raw, as sashimi or sushi, $13 \%$ often cooked salmon as pan fried, deep fried, or grilled, $15 \%$ often cooked salmon as steamed, boiled or stewed, and the final $6 \%$ used other cooking methods. In terms of the venues where consumers eat salmon, $21 \%$ of the respondents often ate salmon at home, $46 \%$ at restaurants, $28 \%$ at both restaurants and home, and $5 \%$ at other venues. Although the methods of preparing salmon are not complicated, almost half of the respondents chose restaurants as their primary salmon consumption venue. This indicates that salmon is relatively new to the Chinese diet and consumers have not gained much experience of preparing it in the kitchen at home.

We asked consumers for their perceptions on attributes of Alaskan wild seafood, including the production environment, taste, and nutritional content. Fifty-seven percent of the respondents perceived Alaska as a high-quality, safe, and clean seafood production environment, while the remaining $43 \%$ did not think so or were not sure. This variable shows consumers' perception of an extrinsic attribute of salmon, which is the production environment. By contrast with farm-raised salmon, which generates many environmental concerns [60,61], the wild salmon "production" procedure is all natural, which does not pollute the environment and its harvesting is also managed in a sustainable way. Although the sustainable environment in the production of salmon in Alaska is not a direct benefit for Chinese consumers, the consequential effect on the premium taste and nutrition of salmon may benefit Chinese consumers more directly. We found $57 \%$ of the respondents perceived 
that Alaskan wild seafood tastes better than farm-raised seafood, and the other $43 \%$ did not think so or were not sure. Fifty-three percent of the respondents perceived Alaskan wild seafood as more nutritious than farm-raised seafood, while $47 \%$ disagreed or were unsure.

To gain an understanding of consumers' potential purchase decisions on wild salmon, we asked consumers to express their intentions to buy wild salmon fillet from Alaska if it is available at an acceptable price while they were shopping on that day. (In the conceptual framework, we showed that the perceived value is determined by perceived quality and price. In the survey, instead of providing objective price or eliciting subjective price, we control price by adding an assumption to the question of "... if it is available at an acceptable price while you were shopping on that day".) We adopted the traditional 5-point purchase intention scale in this question [62]. Respondents answered the question by selecting one of five categorical choices and 19\% of them "Definitely would buy it", $40 \%$ "Probably would buy it", 28.4\% "Might or might not buy it", 9.3\% "Probably would not buy it", and 3.3\% "Definitely would not buy it".

We designed a similar question to ask the consumers to express their intentions to buy wild salmon heads and bones from Alaska assuming they are available at an acceptable price which is much cheaper than salmon fillet while they were shopping on that day. (Heads are the whole heads chopped off from the body with meat in the collar and behind the gills. Bones refer to the remaining part of the fish after the fillets are sliced away from both sides of the salmon body. It usually comes with the skeleton bones and meat attached to it. These two cuts are often displayed alongside with the salmon fillet in supermarkets in China for sale. In addition, we control the price of salmon heads/bones by adding an assumption to the question of " ... assuming they are available at an acceptable price which is much cheaper than salmon fillet while they were shopping on that day".) We found that $18.7 \%$ of the respondents "Definitely would buy it", 37.5\% "Probably would buy it", 24.1\% "Might or might not buy it", $12.6 \%$ "Probably would not buy it", and 7.2\% "Definitely would not buy it".

Since the two questions on stated purchase intentions are similar, a comparison between answers is summarized in Figure 2. The average purchase intentions for heads/bones are lower than those for fillet, but not substantially. However, there are similar percentages of respondents who would definitely buy wild salmon fillet or heads/bones, indicating a segment of consumers who are strongly interested in purchasing wild salmon products from Alaska.

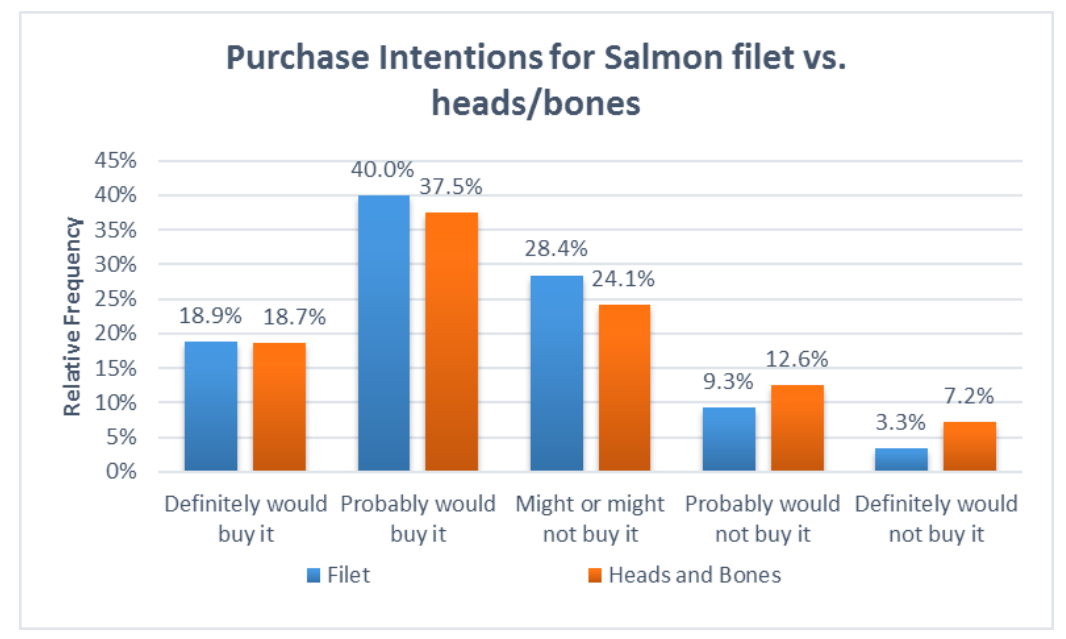

Figure 2. Consumers' purchase intentions for Alaskan wild salmon fillet vs. heads and bones.

\section{Results}

We report the estimation results from the ordered logit model of consumers' purchase intentions for wild salmon fillet and heads/bones, respectively. Heterogeneity of purchase intentions in consumer groups is indicated by the characteristic variables. We describe the model results by interpreting the 
sign and odds ratio of each significant coefficient. (In our interpretation, we simplify the wording of the odds ratio of belonging to a certain category or higher versus that of belonging to the lower categories by the wording of the odds ratio of a greater purchase intention.)

\subsection{Purchasing Wild Salmon Fillet from a Sustainable Production Environment}

Table 3 shows the estimated coefficients and odds ratios in the wild salmon fillet model. First, it reveals that education has an increasingly strong positive influence on consumers' wild salmon fillet purchase intentions. Consumers with an associate, bachelor's or graduate degree tend to have a greater intention to purchase wild salmon fillet than consumers with high school or lower education. The odds of consumers with an associate, bachelor's, and graduate degree having a greater purchase intention are $1.4,1.5$, and 1.8 times, respectively, the odds of consumers with high school or lower education. Second, family size also affects the purchasing intention significantly. The odds of having a greater intention to purchase wild salmon fillet is 1.1 times higher when there is one additional member in the household. Third, interestingly, the income coefficient is insignificant, indicating the intention to purchase wild salmon fillet may be less of a budget-driven, but more of a subjective utility-driven behavior. When the income factor is under control, higher-educated consumers show a higher stated purchase intention due to higher valuation on the health benefits of wild salmon, a feeling of enjoying imported trendy food, or the positive environmental impact of consuming sustainable wild salmon.

Table 3. Ordered logit model for consumers' purchase intentions for wild salmon fillet from Alaska.

\begin{tabular}{llll}
\hline Variable & Coef. & Std. Err. & Odds Ratio \\
\hline male & -0.123 & 0.126 & 0.884 \\
age & 0.005 & 0.005 & 1.005 \\
edu_col & $0.301^{*}$ & 0.181 & 1.351 \\
edu_ba & $0.401^{* *}$ & 0.176 & 1.493 \\
edu_grad & $0.588^{* * *}$ & 0.226 & 1.800 \\
hhnum & $0.102^{* *}$ & 0.045 & 1.108 \\
d_child & -0.072 & 0.139 & 0.931 \\
income & -0.010 & 0.011 & 0.990 \\
inc_in & $0.207^{*}$ & 0.123 & 1.230 \\
inc_de & -0.452 & 0.348 & 0.637 \\
migrant & 0.012 & 0.143 & 1.012 \\
city_SH & $0.317^{* *}$ & 0.151 & 1.374 \\
city_GZ & 0.025 & 0.152 & 1.025 \\
harvest_wild & $1.052^{* * *}$ & 0.186 & 2.864 \\
harvest_both & $0.790^{* * *}$ & 0.159 & 2.203 \\
harvest_farm & $0.367^{*}$ & 0.217 & 1.443 \\
pres_water & -0.332 & 0.226 & 0.718 \\
pres_chill & -0.317 & 0.289 & 0.728 \\
pres_froze & $-0.814 * *$ & 0.341 & 0.443 \\
cook_raw & 0.145 & 0.185 & 1.156 \\
cook_stew & -0.040 & 0.223 & 0.961 \\
cook_other & 0.567 & 0.438 & 1.763 \\
place_home & $0.980^{* * *}$ & 0.188 & 2.665 \\
place_both & $0.697^{* * *}$ & 0.148 & 2.008 \\
place_other & $-1.358^{* * *}$ & 0.476 & 0.257 \\
clean & $0.519^{* * *}$ & 0.135 & 1.680 \\
tastey & $0.375^{* * *}$ & 0.143 & 1.454 \\
nutritious & 0.219 & 0.142 & 1.245 \\
$\mu 1$ & -1.585 & 0.465 & \\
$\mu 2$ & -0.023 & 0.441 & \\
$\mu 3$ & 1.804 & 0.441 & \\
$\mu 4$ & 3.956 & 0.456 & \\
\hline ; $* * *$ and *indicate & significance level at $1 \%, 5 \%$, and $10 \%$, respectively. \\
& & & \\
& & & \\
& & &
\end{tabular}

Consumers, whose income has increased over the last two years have greater purchase intentions than consumers whose income did not change. However, a decrease of income does not impose a significant effect on the purchase intention. The odds of consumers experiencing an income increase having a greater purchase intention are 1.2 times the odds of consumers whose income stayed the 
same. This is consistent with the observations that the rising middle class with higher disposable income has been following the world's leading trend in food consumption and generating demand for high-quality food, especially food from clean and safe sources [63].

The odds of Shanghai consumers having a greater purchase intention are 1.4 times the odds of Beijing consumers, while Guangzhou consumers show no difference in the comparison with the base group of Beijing consumers. Shanghai, a global financial center and transport hub, has experienced the fastest development during the economic boom in China. Consumers in this city have been exposed to high-quality domestic and imported food products and also have been the consumption trend setter in the country [64].

Consumers who often purchase wild seafood, farm-raised seafood, or both wild and farm-raised seafood have a greater intention to buy wild salmon fillet than the base-group consumers who do not pay attention to or do not understand the difference between the two production methods. The odds of consumers who often buy wild seafood, both wild and farm-raised, and farm-raised seafood are 2.9, 2.2 and 1.4 times, respectively, the odds of those who do not pay attention to or do not understand the difference. Thus, it is more likely for consumers to express purchase intentions for Alaskan wild salmon fillet and make purchase decisions when they are familiar with the distinction between wild and farm-raised seafood, especially if they have established a preference for wild seafood due to prior consumption experience.

Consumers who prefer to buy frozen seafood have a lower intention to purchase wild salmon fillet, with odds approximately half of those who do not have a preference for seafood preservation methods. On the other hand, those who prefer live fish and chilled fish have similar salmon fillet purchase intentions as the base group of consumers with no preference for preservation methods. Since salmon was first introduced to China as sashimi or sushi in Japanese cuisine, consumers tend to associate salmon with the fresh and unfrozen form. As shown in Table 2, 66\% of the respondents choose raw sashimi or sushi as the primary method of eating salmon, while the most common Chinese fish-cooking methods of steaming, boiling or stewing only account for 15\%, far behind the first category. Although most Chinese consumers usually buy live fish from water tanks, as reported in Table 2, there is a small number of consumers preferring frozen fish due to preservation convenience. Consumers who always buy frozen fish will be less likely to buy salmon if they believe it should be eaten raw.

Consumers who often eat salmon at home, or at both home and restaurants, have a greater intention to buy wild salmon fillet than consumers who often eat salmon only at restaurants, with the odds ratios of a greater purchase intention being 2.7 and 2.0, respectively. It is straightforward to think that, for the consumers who eat salmon mostly at restaurants, they may not have a high intention to buy the fillet products from markets compared with consumers who eat salmon mainly at home. Those who eat salmon at places other than home or restaurants showed lower intentions to buy salmon fillet than even the restaurant diners. The "other places" mean places like friends' or relatives' homes, and these people tend to be marginal consumers of such products whose purchasing intention is only $26 \%$ of those restaurant diners. Furthermore, consumers eating at home pay attention to the nutrition content and health benefits of food more than those dining at restaurants [65]. Thus, consumers may be more likely to purchase this healthy product for home consumption. There is no statistically significant impact of the difference in salmon-cooking methods on consumer's purchase intention for wild salmon fillet.

Consumers who perceive Alaska to be a high-quality, safe, and clean seafood production environment have a higher purchase intention to buy wild salmon fillet, with an odds ratio of a greater purchase intention 1.7 times the odds of consumers who do not have such a perception. Consumers who think Alaskan wild seafood tastes better than farm-raised seafood have an odds ratio of a greater purchase intention of 1.5 times the odds of consumers who do not perceive this. Hence, consumers' positive perception on production environment and premium taste significantly affects their potential purchase on sustainable wild salmon fillet. Since these two variables are included in the ordered logit regression model with multiple variables, the effects of perceptions on the extrinsic and 
intrinsic attributes can be interpreted in a ceteris paribus way, i.e., given the salmon tastes the same and all other attributes remain the same, the positive perception of the production environment will increase consumers' purchasing intention 1.7 times, and vice versa.

\subsection{Sustainable Consumption of Wild Salmon Varietal Parts to Minimize Waste}

Typical western salmon consumers do not have the culinary tradition of eating varietal parts of fish. Fish processors usually discard the varietal parts of the fish as waste or utilize them as low-value ingredients in feed or pet-food products. By contrast, in China fish head is a popular food among consumers and one of the most consumed fish parts [66]. Thus, from the perspective of Chinese consumers, the heads and bones of wild salmon of premium quality can be efficiently utilized and built into a healthy diet.

Table 4 presents the estimation results from the ordered logit model of consumers' purchase intentions for wild salmon heads and bones. We proceed in a similar fashion as the previous section to interpret the significant coefficients and odds ratios. The odds of consumers with associate degrees or vocational college having a higher purchase intention are 1.4 times the odds of consumers with high school or lower education. The bachelor's and graduate degree holders do not show a higher purchase intention than the base-group, high school, or lower-educated consumers. Although fish heads and bones are considered healthy meals in Chinese culinary tradition, they are not high-end products compared to the fillet cuts and may not be appealing to the consumers with higher education which is a proxy for a higher social status in China.

Table 4. Ordered logit model for consumers' purchase intentions for wild salmon heads/bones from Alaska.

\begin{tabular}{|c|c|c|c|}
\hline Variable & Coef. & Std. Err. & Odds Ratio \\
\hline Male & -0.179 & 0.123 & 0.836 \\
\hline Age & -0.003 & 0.005 & 0.997 \\
\hline edu_col & $0.362 * *$ & 0.178 & 1.436 \\
\hline$e d u \_b a$ & 0.196 & 0.172 & 1.216 \\
\hline edu_grad & 0.284 & 0.22 & 1.328 \\
\hline Hhnum & 0.026 & 0.042 & 1.026 \\
\hline d_child & -0.165 & 0.136 & 0.848 \\
\hline Income & $-0.026 * *$ & 0.011 & 0.974 \\
\hline inc_in & $0.319^{* * *}$ & 0.121 & 1.375 \\
\hline inc_de & -0.088 & 0.334 & 0.916 \\
\hline Migrant & -0.009 & 0.14 & 0.991 \\
\hline city_SH & 0.013 & 0.15 & 1.013 \\
\hline city_GZ & 0.216 & 0.149 & 1.241 \\
\hline harvest_wild & $1.261^{* * *}$ & 0.184 & 3.529 \\
\hline harvest_both & $0.631^{* * *}$ & 0.154 & 1.879 \\
\hline harvest_farm & 0.191 & 0.206 & 1.211 \\
\hline pres_water & $-0.423 *$ & 0.217 & 0.655 \\
\hline pres_chill & -0.396 & 0.276 & 0.673 \\
\hline pres_froze & $-1.180^{* * *}$ & 0.329 & 0.307 \\
\hline cook_raw & -0.052 & 0.183 & 0.95 \\
\hline cook_stew & 0.229 & 0.22 & 1.258 \\
\hline cook_other & 0.204 & 0.432 & 1.227 \\
\hline place_home & $0.523^{* * *}$ & 0.182 & 1.686 \\
\hline place_both & $0.252 *$ & 0.147 & 1.287 \\
\hline place_other & $-0.798^{*}$ & 0.459 & 0.45 \\
\hline Clean & $0.528^{* * *}$ & 0.131 & 1.695 \\
\hline Tasty & 0.032 & 0.14 & 1.033 \\
\hline Nutritious & $0.298^{* *}$ & 0.138 & 1.347 \\
\hline$\mu 1$ & -2.129 & 0.435 & \\
\hline$\mu 2$ & -0.900 & 0.424 & \\
\hline$\mu 3$ & 0.391 & 0.422 & \\
\hline$\mu 4$ & 2.359 & 0.43 & \\
\hline
\end{tabular}


Consumers with higher household income have a lower purchase intention for wild salmon heads/bones, again because these varietal parts are not considered as high-end products and there is no positive income effect on the purchase intentions. The odds of a greater purchase intention decrease to 0.97 for consumers earning each 10,000 Yuan higher annual income. However, income increase over the last two years causes consumers to have a higher intention to buy wild salmon heads/bones, consistent with the effect on salmon fillet purchase intention. The odds of consumers with an increased income having a greater purchase intention are 1.4 times the odds of consumers with no income change. This indicates that it is the increase in income, instead of the relative level of income, which stimulates Chinese consumers to adopt new spending behaviors and explore new products. This is in line with the observed consumption pattern changes of the emerging middle class who experience an upgrade in economic and social status [67].

Consumers who often purchase wild seafood or both wild and farm-raised seafood have a higher intention to buy wild salmon heads/bones than consumers who do not pay attention to or do not understand the difference between wild and farm-raised seafood. The odds of a higher purchase intention for the two segments of consumers are 3.5 and 1.9 times, respectively. This is consistent with the findings for fillet purchase. Prior experience and preference for wild seafood make it easier for consumers to purchase wild salmon parts.

Consumers who often buy frozen seafood have a lower intention to purchase wild salmon heads/bones than consumers who do not have a strict preference for particular seafood preservation methods. The odds of consumers who often buy frozen seafood are 0.3 times the odds of consumers who do not have a strict preference for particular seafood preservation methods. Consumers who often eat salmon at home, or both at home and restaurants, have a greater intention to buy wild salmon heads/bones than consumers who often eat salmon at restaurants. The odds of these two types of consumers are 1.7 and 1.3 times, respectively, the odds of consumers who often eat salmon at restaurants. There is no statistically significant impact of the seafood cooking method on purchase intentions for wild salmon heads/bones.

Consumers who perceive Alaska as a high-quality, safe, and clean seafood production environment have a higher purchase intention to buy wild salmon heads/bones, with an odds ratio of a greater purchase intention 1.7 times the odds of consumers who do not have such a perception. This is similar to the wild salmon fillet case; Chinese consumers having a positive perception on the extrinsic environment attribute show a greater purchase intention. By contrast with the results on fillet purchase intentions, consumers' perceptions of the taste of wild seafood does not affect their purchase intentions for wild salmon heads and bones. Instead, consumers who believe Alaskan wild seafood to be more nutritious than farm-raised seafood have an odds ratio of a greater purchase intention 1.3 times the odds of consumers who do not perceive this. The results reflect the fact that Chinese consumers view fish heads and bones as healthy ingredients and value the nutrition content of the heads/bones products. They will show a greater purchase intention, especially when these healthy ingredients are from natural, wild, and sustainable production environments.

\section{Discussions and Conclusions}

Due to the rapidly expanding trade and globalized market for food products, sustainable food consumption and production is becoming a global trend that brings a better quality of life while minimizing waste and pollution. China is a rapidly emerging economy with the largest population and one of the largest consumer markets in the world. Chinese consumers' food consumption patterns play an important role on the structure of global trade flows, sustainable ecosystems and the environment. Although wild salmon does not currently account for a large share of the Chinese market, Chinese consumers' significant purchase intentions for wild salmon fillet and head/bones indicate an emerging new market potential for wild seafood from natural, clean and sustainable production environments. 
In this study, we identified important factors that have effects on Chinese consumers' purchase intentions, including their seafood and salmon-specific consumption habits, perceptions on intrinsic and extrinsic seafood attributes, and social demographic characteristics. For both wild salmon fillet and head/bones, consumers whose incomes have increased over the last two years show a greater purchase intention. Improvement in disposable income and, thus, living conditions, allow Chinese consumers to gain the capacity to explore higher-quality diet options and be able to afford natural and sustainable food products. Consumers who have prior experience in purchasing wild seafood or well-built preferences for wild seafood have greater purchase intentions. As a result, to promote the sustainable consumption and production concept and the health benefits from the food produced following sustainable fishery practice, this segment of consumers will be the first group of supporters. Educating consumers and creating opportunities for them to gain experience and gradually build preference may be an efficient strategy.

In the meantime, while western cuisine has various ways to cook salmon (such as grill, pan fry, oven broil, or smoke), currently the Chinese cooking methods for salmon are limited; most consumers (66\% as reported in Table 2) mainly eat it raw as sashimi or sushi. That may explain why we do not find significant effects of salmon cooking methods on purchase intentions. However, consumers who often eat salmon at home have a greater intention to purchase wild salmon fillet and head/bones than consumers who often eat salmon at restaurants. This implies that consumers may pay more attention to the nutrition facts of the food when eating at home. It will be more effective to introduce wild salmon to Chinese consumers if they are provided with various home recipes for cooking salmon.

Although consumers in our survey stated a strong intention to purchase both wild salmon fillet and heads/bones, there is difference between their preferences for fillet and parts. Consumers with higher education, in a larger household, located in Shanghai have a greater intention to purchase wild salmon fillet, but not salmon heads/bones. In addition, consumers with higher income have a lower intention to purchase wild salmon heads/bones.

An important result of this study is that consumers' positive perceptions on the safe, natural and sustainable production environment and premium taste (arguably due to sustainable wild fishery practice) play a significant role in their purchase intentions for wild salmon fillet. Positive perceptions of the production environment with a higher nutrition content for wild seafood causes consumers to have greater purchase intentions for wild salmon heads/bones.

These results suggest that the wild salmon industry can improve its Chinese market by targeting their campaign to the educated urban consumers who experience income rises and who often consume other wild seafood at home. Using the natural and clean environment as a promotion message can also improve the wild salmon sale. With increased demand, the industry will be able to generate higher revenue; it may even refrain from increasing the catching of wild fish, and can use the revenue to further invest in sustainable production technology.

Due to many differences in culinary traditions in fish consumption between western countries and China, Chinese consumers show promising purchase intentions for varietal parts of wild salmon, as revealed by our study. In particular, we believe the seemingly low-value parts of Alaskan wild salmon can potentially carry significant economic value as seafood products to be exported to China. However, a cost-effective business model, which includes an efficient logistics/transportation strategy and reasonable pricing for different salmon fish parts based on a consumer's preference, is important for this to happen. We believe that our study is an important step to help build such a business model, which can then create a win-win situation for the consumers in importing countries, the producers in exporting countries, and the entire global supply chain in order to efficiently allocate resources, feed people with healthy food, avoid food waste, and fulfill the economic value of products.

Author Contributions: Qiujie Zheng and H. Holly Wang conceptualized the idea and designed the survey; Qiujie Zheng, H. Holly Wang and Yonggang Lu estimated the model, interpreted the results and wrote the paper. 
Acknowledgments: Funding support from the University of Alaska Anchorage Vice Provost of Research and Graduate Studies 2015 Innovate Awards is gratefully acknowledged. We thank the Alaska Seafood Marketing Institute for sharing research information, and Yiming Wu and students at Guangdong University of Foreign Studies, Xi Zhu and students at Shanghai Jiao Tong University, and students at Renmin University of China for assisting with data collection. We also thank the editor and two anonymous reviewers for constructive comments that have helped us improve the quality of this study significantly.

Conflicts of Interest: The authors declare no conflict of interest.

\section{References}

1. Vermeir, I.; Verbeke, W. Sustainable food consumption: Exploring the consumer "attitude-behavioral intention" gap. J. Agric. Environ. Ethics 2006, 19, 169-194. [CrossRef]

2. Kantor, L.S.; Lipton, K.; Manchester, A.; Oliveira, V. Estimating and addressing America's food losses. Food Rev. 1997, 20, 2-12.

3. Wang, L.; Cai, Y.; Fang, L. Pollution in Taihu Lake China: Causal chain and policy options analyses. Front. Earth Sci. China 2009, 3, 437. [CrossRef]

4. Fabinyi, M. Historical, cultural and social perspectives on luxury seafood consumption in China. Environ. Conserv. 2012, 39, 83-92. [CrossRef]

5. FAOSTAT. Food and Agriculture Organization of the United Nations Food and Agriculture Data. Available online: http:/ / www.fao.org/faostat/en/\#home (accessed on 11 January 2018).

6. Fabinyi, M. Sustainable seafood consumption in China. Mar. Policy 2016, 74, 85-87. [CrossRef]

7. Salov, A. Working with China Alaska's growing export partner. Alaska Bus. Mon. February 2012. Available online: http:/ / www.wtcak.org/PDF2012/QandASalov.pdf (accessed on 11 January 2018).

8. Food and Agriculture Organization (FAO). The State of World Fisheries and Aquaculture 2016. Available online: http:/ / www.fao.org/3/a-i5555e.pdf (accessed on 11 January 2018).

9. Liu, H. Joyvio Agriculture's strategies in seafood consumption industry (in Chinese). Available online: http:/ / www.sohu.com/a/194290749_115495 (accessed on 11 January 2018).

10. Alaska Seafood Marketing Institute (ASMI). FY 2014-2015 Unified Export Strategy; Report; Alaska Seafood Marketing Institute: Juneau, AK, USA, 2013.

11. Verbeke, W.; Ward, R.W. A fresh meat almost ideal demand system incorporating negative TV press and advertising impact. Agric. Econ. 2001, 25, 359-374. [CrossRef]

12. Piggott, N.E.; Marsh, T.L. Does food safety information impact US meat demand? Am. J. Agric. Econ. 2004, 86, 154-174. [CrossRef]

13. Wang, H.H.; Beville, P.G. The media impact of animal disease on the US meat demand. Agribusiness 2017, 33, 493-504. [CrossRef]

14. Bennett, R.M. People's willingness to pay for farm animal welfare. Anim. Welf. 1996, 5, 3-11.

15. Napolitano, F.; Pacelli, C.; Girolami, A.; Braghieri, A. Effect of information about animal welfare on consumer willingness to pay for yogurt. J. Dairy Sci. 2008, 91, 910-917. [CrossRef] [PubMed]

16. Tonsor, G.T.; Olynk, N.; Wolf, C. Consumer preferences for animal welfare attributes: The case of gestation crates. J. Agric. Appl. Econ. 2009, 41, 713-730. [CrossRef]

17. De Pelsmacher, P.; Driesen, L.; Rayp, G. Do consumers care about ethics? Willingness to pay for fair-trade coffee. J. Consum. Aff. 2005, 39, 363-385. [CrossRef]

18. Basu, A.K.; Hicks, R.L. Label performance and the willingness to pay for fair trade coffee: A cross-national perspective. Int. J. Consum. Stud. 2008, 32, 470-478. [CrossRef]

19. Drichoutis, A.C.; Vassilopoulos, A.; Lusk, J.L.; Nayga, R.M. Consumer preferences for fair labour certification. Eur. Rev. Agric. Econ. 2017, 44, 455-474. [CrossRef]

20. Buzby, J.C.; Fox, J.A.; Ready, R.C.; Crutchfield, S.R. Measuring consumer benefits of food safety risk reductions. J. Agric. Appl. Econ. 1998, 30, 69-82. [CrossRef]

21. Lusk, J.L.; Norwood, F.B.; Pruitt, J.R. Consumer demand for a ban on antibiotic drug use in pork production. Am. J. Agric. Econ. 2006, 88, 1015-1033. [CrossRef]

22. Costa-Font, M.; Gil, J.M.; Traill, W.B. Consumer acceptance, valuation of and attitudes towards genetically modified food: Review and implications for food policy. Food Policy 2008, 33, 99-111. [CrossRef]

23. Loureiro, M.L.; Umberger, W.J. Estimating consumer willingness to pay for country-of-origin labeling. J. Agric. Resour. Econ. 2003, 28, 287-301. 
24. Loureiro, M.L.; Umberger, W.J. Assessing consumer preferences for country-of-origin labeling. J. Agric. Appl. Econ. 2005, 37, 49-63. [CrossRef]

25. Loureiro, M.L.; Umberger, W.J. A choice experiment model for beef: What US consumer responses tell us about relative preferences for food safety, country-of-origin labeling and traceability. Food Policy 2007, 32, 496-514. [CrossRef]

26. Wang, H.H.; Zhang, X.; Ortega, D.L.; Olynk Widmar, N.J. Information on food safety, consumer preference and behavior: The case of seafood in the US. Food Control 2013, 33, 293-300. [CrossRef]

27. Hoffmann, R. Country of origin-A consumer perception perspective of fresh meat. Br. Food J. 2000, 102, 211-229. [CrossRef]

28. Blend, J.R.; Van Ravenswaay, E.O. Measuring consumer demand for ecolabeled apples. Am. J. Agric. Econ. 1999, 81, 1072-1077. [CrossRef]

29. Johnston, R.J.; Wessells, C.R.; Donath, H.; Asche, F. Measuring consumer preferences for ecolabeled seafood: An international comparison. J. Agric. Resour. Econ. 2001, 26, 20-39.

30. Loureiro, M.L.; McCluskey, J.J. Will consumers pay a premium for eco-labeled apples? J. Consum. Aff. 2002, 36, 203-219. [CrossRef]

31. Gil, J.M.; Sanchez, G.M. Market segmentation and willingness to pay for organic products in Spain. Int. Food Agribus. Manag. Rev. 2000, 3, 207-226. [CrossRef]

32. Magnusson, M.K.; Arvola, A.; Hursti, U.K.K.; Åberg, L.; Sjödén, P.O. Choice of organic foods is related to perceived consequences for human health and to environmentally friendly behaviour. Appetite 2003, 40, 109-117. [CrossRef]

33. Batte, M.T.; Hooker, N.H.; Haab, T.C.; Beaverson, J. Putting their money where their mouths are: Consumer willingness to pay for multi-ingredient processed organic food products. Food Policy 2007, 32, 145-159. [CrossRef]

34. Hughner, R.S.; McDonagh, P.; Prothero, A.; Shultz, C.J.; Stanton, J. Who are organic food consumers? A compilation and review of why people purchase organic food. J. Consum. Behav. 2007, 6, 94-110. [CrossRef]

35. Lai, J.; Wang, H.H.; Ortega, D.L.; Olynk Widmar, N.J. Factoring Chinese consumers' risk perceptions into their willingness to pay for pork safety, environmental stewardship, and animal welfare. Food Control 2018, 85, 423-431. [CrossRef]

36. Yin, S.; Wu, L.; Du, L.; Chen, M. Consumers' purchase intention of organic food in China. J. Sci. Food Agric. 2010, 90, 1361-1367. [CrossRef] [PubMed]

37. Paul, J.; Rana, J. Consumer behavior and purchase intention for organic food. J. Consum. Mark. 2012, 29, 412-422. [CrossRef]

38. Thøgersen, J.; de Barcellos, M.D.; Perin, M.G.; Zhou, Y. Consumer buying motives and attitudes towards organic food in two emerging markets. Int. Mark. Rev. 2015, 32, 389-413. [CrossRef]

39. Xie, B.; Wang, L.; Yang, H.; Wang, Y.; Zhang, M. Consumer perceptions and attitudes of organic food products in eastern china. Br. Food J. 2015, 117, 1105-1121. [CrossRef]

40. Thøgersen, J.; Zhou, Y. Chinese consumers' adoption of a 'green' innovation-The case of organic food. J. Mark. Manag. 2012, 28, 313-333. [CrossRef]

41. Shi, Y.; Cheng, C.; Lei, P.; Wen, T.; Merrifield, C. Safe food, green food, good food: Chinese Community Supported Agriculture and the rising middle class. Int. J. Agric. Sustain. 2011, 9, 551-558. [CrossRef]

42. Lang, T.; Barling, D.; Caraher, M. Food Policy: Integrating Health, Environment and Society; Oxford University Press: Oxford, UK, 2009.

43. Aschemann-Witzel, J. Consumer perception and trends about health and sustainability: Trade-offs and synergies of two pivotal issues. Curr. Opin. Food Sci. 2015, 3, 6-10. [CrossRef]

44. Bisogni, C.A.; Jastran, M.; Seligson, M.; Thompson, A. How people interpret healthy eating: Contributions of qualitative research. J. Nutr. Educ. Behav. 2012, 44, 282-301. [CrossRef] [PubMed]

45. Hoek, A.C.; Pearson, D.; James, S.W.; Lawrence, M.A.; Friel, S. Shrinking the food-print: A qualitative study into consumer perceptions, experiences and attitudes towards healthy and environmentally friendly food behaviours. Appetite 2017, 108, 117-131. [CrossRef] [PubMed]

46. Morrison, D.G. Purchase intentions and purchase behavior. J. Mark. 1979, 43, 65-74. [CrossRef]

47. Whitlark, D.B.; Geurts, M.D.; Swenson, M.J. New product forecasting with a purchase intention survey. J. Bus. Forecast. Methods Syst. 1993, 12, 18-21. 
48. Laroche, M.; Kim, C.; Zhou, L. Brand familiarity and confidence as determinants of purchase intention: An empirical test in a multiple brand context. J. Bus. Res. 1996, 37, 115-120. [CrossRef]

49. Brown, M.; Pope, N.; Voges, K. Buying or browsing? An exploration of shopping orientations and online purchase intention. Eur. J. Mark. 2003, 37, 1666-1684. [CrossRef]

50. Yeon Kim, H.; Chung, J.E. Consumer purchase intention for organic personal care products. J. Consum. Mark. 2011, 28, 40-47. [CrossRef]

51. Hartmann, P.; Apaolaza-Ibáñez, V. Consumer attitude and purchase intention toward green energy brands: The roles of psychological benefits and environmental concern. J. Bus. Res. 2012, 65, 1254-1263. [CrossRef]

52. Dodds, W.B.; Monroe, K.B.; Grewal, D. Effects of price, brand, and store information on buyers' product evaluations. J. Mark. Res. 1991, 28, 307-319. [CrossRef]

53. Chang, T.Z.; Wildt, A.R. Price, product information, and purchase intention: An empirical study. J. Acad. Mark. Sci. 1994, 22, 16-27. [CrossRef]

54. Hui, M.K.; Zhou, L. Linking product evaluations and purchase intention for Country-of-Origin effects. J. Glob. Mark. 2002, 15, 95-116. [CrossRef]

55. Kumar, A.; Lee, H.J.; Kim, Y.K. Indian consumers' purchase intention toward a United States versus local brand. J. Bus. Res. 2009, 62, 521-527. [CrossRef]

56. Sheth, J.N.; Newman, B.I.; Gross, B.L. Consumption Values and Market Choice; South Western Publishing: Cincinnati, OH, USA, 1991.

57. Sheth, J.N.; Newman, B.I.; Gross, B.L. Why we buy what we buy: A theory of consumption values. J. Bus. Res. 1991, 22, 159-170. [CrossRef]

58. Sweeney, J.C.; Soutar, G.N. Consumer perceived value: The development of a multiple item scale. J. Retail. 2001, 77, 203-220. [CrossRef]

59. Train, K.E. Discrete Choice Methods with Simulation; Cambridge University Press: New York, NY, USA, 2009; pp. 182-186, ISBN 9780521747387.

60. Easton, M.D.L.; Luszniak, D.; Von der Geest, E. Preliminary examination of contaminant loadings in farmed salmon, wild salmon and commercial salmon feed. Chemosphere 2002, 46, 1053-1074. [CrossRef]

61. Hites, R.A.; Foran, J.A.; Carpenter, D.O.; Hamilton, M.C.; Knuth, B.A.; Schwager, S.J. Global assessment of organic contaminants in farmed salmon. Science 2004, 303, 226-229. [CrossRef] [PubMed]

62. Jamieson, L.F.; Bass, F.M. Adjusting stated intention measures to predict trial purchase of new products: A comparison of models and methods. J. Mark. Res. 1989, 26, 336-345. [CrossRef]

63. Zipser, D.; Chen, Y.; Gong, F. The Modernization of the Chinese Consumer. McKinsey \& Company 2016 China Consumer Report. Available online: http:/ / mckinseychina.com/wp-content/uploads/2016/03/TheModernization-of-the-Chinese-Consumer_EN.pdf (accessed on 11 January 2018).

64. HKTDC Research. Shanghai: Market Profile. Available online: http://china-trade-research.hktdc.com/ business-news/article/Facts-and-Figures/Shanghai-Market-Profile/ff/en/1/1X000000/1X06BVOR.htm (accessed on 11 January 2018).

65. Zheng, Q.; Wang, H.H. Chinese Preferences for Sustainable Attributes for Food Away From Home: A Rank-Ordered Model. China Econ. Rev. 2016, 41, 148-158. [CrossRef]

66. Zheng, Q.; Wang, H.H.; Fong, Q.; Lu, Y. Consumer Preference and Market Potential for Alaska Salmon in China: Preliminary Analysis. Alaska Sea Grant 2017, University of Alaska Fairbanks, MAB-70, Fairbanks. Available online: http: / / doi.org/10.4027/cpmpaspa.2017 (accessed on 11 January 2018).

67. Wang, H.H. Five New Trends of Chinese Consumers. Forbes. Available online: https://www.forbes.com/ sites/helenwang/2012/12/17 / five-new-trends-of-chinese-consumers / (accessed on 11 January 2018).

(C) 2018 by the authors. Licensee MDPI, Basel, Switzerland. This article is an open access article distributed under the terms and conditions of the Creative Commons Attribution (CC BY) license (http://creativecommons.org/licenses/by/4.0/). 